\title{
Agency Theory in Marketing: An Abstract
}

\author{
Raeesah Chohan
}

\begin{abstract}
Marketers often depend on third parties to do the work for them, such as advertising or research agencies and distributors of goods and services (Bergen et al. 1992). Agency theory provides a strong and apposite conceptual framework to understand and explain these associations. In these relationships, a party called the principal assigns work to another party called the agent, who then does the work (Eisenhardt 1989). For example, salespeople and their managers share an agency relationship, where the manager is the principal and the salesperson is the agent. As agency relationships prevail in real-world marketing issues (Bergen et al. 1992), a better understanding of the role of agency theory in marketing is important to marketing scholars and is valuable to practitioners.

Twenty-six years have elapsed since Bergen et al. (1992) published their work on agency theory in marketing. Agency theory is still relevant in marketing today. However, since 1992, there has been no other thorough update of the literature on agency theory in marketing-related contexts despite the various developments in marketing, such as the advent of the Internet. In this paper, I provide an updated review of the literature on agency theory in marketing-related contexts, namely, salesforce management and compensation plans, business-to-consumer marketing, business-to-business marketing, advertising agency-client relationships, marketing management and shareholders, and sponsorships. I also identify new avenues for research on agency theory in marketing.
\end{abstract}

References Available Upon Request

\author{
R. Chohan $(\bowtie)$ \\ University of Cape Town, Cape Town, South Africa \\ e-mail: raeesah.chohan@uct.ac.za
}

